\title{
VIVÊNCIA DE PUÉRPERAS DIANTE DA ASSISTÊNCIA OBSTÉTRICA NO PROCESSO PARTURITIVO
}

PUERPERAL WOMEN'S EXPERIENCE IN FACE OF OBSTETRIC CARE DURING THE PARTURITIVE PROCESS

VIVENCIA DE PUÉRPERAS ANTE LA ATENCIÓN OBSTÉTRICA EN EL PROCESO PARTURITIVO

Quelrinele Vieira Guimarães ${ }^{1}$

Luana Pereira Ibiapina Coêlho 2

Monyka Brito Lima dos Santos ${ }^{3}$

Ana Carla Marques da Costa 4

Beatriz Mourão Pereira ${ }^{5}$

Joanne Thalita Pereira Silva 6

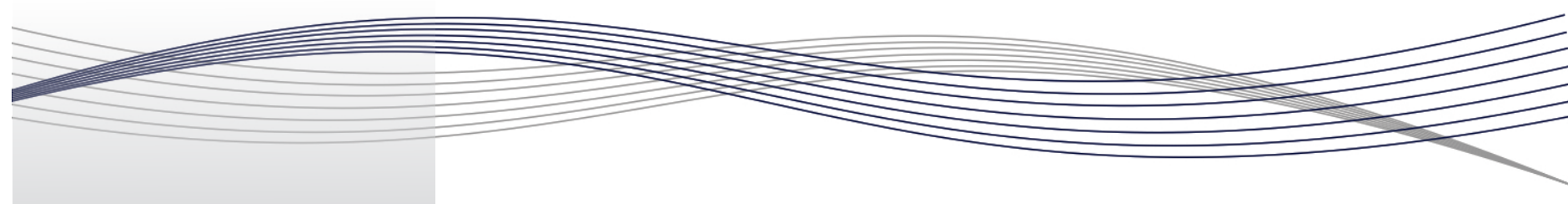

Palavras-chave:

Obstetricia; Enfermagem Obstétrica; Trabalho de Parto.

Keywords:

Obstetrics; Obstetric Nursing; Labor, Obstetric.

Palabras clave: Obstetricia; Enfermería Obstétrica; Trabajo de Parto.

Submetido: 04/03/2020

Aprovado: 11/05/2020

Autor(a) para Correspondência: Quelrinele Vieira Guimarães R. Travessa da Faveira, 2222 Refinaria - Caxias (MA) CEP: 65600-220

E-mail:quelrinele@hotmail.

\section{RESUMO}

Este estudo teve por objetivo analisar a vivência das puérperas na assistência obstétrica recebida no processo parturitivo. Trata-se de estudo exploratório descritivo, com abordagem qualitativa, conduzido com 20 puérperas em maternidade pública no Município de Caxias (MA), em dezembro de 2019 e janeiro de 2020. As falas foram submetidas à Análise de Conteúdo proposta por Laurence Bardin, que possibilitou a adoção de 4 categorias temáticas: a) Atendimento no acolhimento e classificação de risco da maternidade; b) Técnicas e condutas empregadas na assistência pré-parto; c) Técnicas e condutas empregadas na assistência ao parto; e d) Satisfação da puérpera sobre a assistência. 0 estudo revelou que a maioria das puérperas apresentou bom nível de satisfação em relação à assistência obstétrica, mas ainda há profissionais que recorrem a técnicas intervencionistas desnecessárias. Por isso, é essencial a capacitação dos profissionais que integram a equipe multidisciplinar de assistência ao parto, incentivando que adotem ações e técnicas humanizadas e que implantem uma efetiva educação em saúde à gestante durante as consultas pré-natal, para reconstruir sua autonomia, otimizar sua tomada de decisões junto à equipe de saúde e alcançar pleno domínio de seu próprio corpo.

\footnotetext{
1. Enfermeira. Residente em Enfermagem Obstétrica na Universidade Estadual do Maranhão (UEMA). E-mail: quelrinele@hotmail.com 0RCID: https://orcid.org/0000-0003-0375-2702

2. Enfermeira. Residente em Enfermagem Obstétrica na UEMA. E-mail: luana_ibiapina@hotmail.com 0RCID: https://orcid.org/0000-0002-2054-959X

3. Enfermeira. Graduada pelo Centro Universitário de Ciências e Tecnologia do Maranhão (UniFacema). E-mail: monyka.brito@hotmail.com 0RCID: https://orcid.org/0000-0002-6866-9435

4. Enfermeira. Doutora em Biologia Celular e Molecular Aplicada à Saúde pela Universidade Luterana do Brasil (Ulbra). E-mail: carlama271@gmail.com 0RCID: https://orcid.org/0000-0002-4246-145X

5. Enfermeira. Mestre em Biodiversidade, Ambiente e Saúde pela UEMA. E-mail: beatrizmouraopereira@gmail.com ORCID: https://orcid.org/0000-0001-8541-4031

6. Enfermeira. Especialista em Enfermagem 0bstétrica pela Faculdade IESM. E-mail: joanne_thalita@hotmail.com ORCID: https://orcid.org/0000-0001-7810-0069
} 


\section{ABSTRACT}

This study aimed to analyze puerperal women's experience in face of the obstetric care received during the parturitive process. This is a descriptive exploratory study, with a qualitative approach, conducted with 20 puerperal women at a public maternity hospital in the Municipality of Caxias, Maranhão, Brazil, in December 2019 and January 2020. The speeches underwent Content Analysis as proposed by Laurence Bardin, which enabled the adoption of 4 thematic categories: a) Patient's embracement and risk classification at the maternity hospital; b) Techniques and behaviors deployed in pre-delivery care; c) Techniques and behaviors deployed in childbirth care; and d) Puerperal women's satisfaction with care. The study revealed that most puerperal women had a good satisfaction level regarding obstetric care, but there are still practitioners who resort to unnecessary interventionist techniques. Hence, it is key to provide the members of the multidisciplinary childbirth care team with training, encouraging them to adopt humanized actions and techniques and an effective deployment of health education for pregnant women during prenatal care appointments, rebuilding their autonomy, optimizing their decision-making along with the health team, and achieving full control of their own bodies.

\section{RESUMEN}

Este estudio tuvo como objetivo analizar la vivencia de puérperas ante la atención obstétrica recibida en el proceso parturitivo. Este es un estudio exploratorio descriptivo, con un enfoque cualitativo, realizado con 20 puérperas en una maternidad pública en el Municipio de Caxias, Maranhão, Brasil, en diciembre de 2019 y enero de 2020. Las hablas fueron sometidas al Análisis de Contenido propuesto por Laurence Bardin, lo que ha permitido la adopción de 4 categorías temáticas: a) Atención en el acogimiento y clasificación de riesgo de la maternidad; b) Técnicas y conductas empleadas en la atención preparto; c) Técnicas y conductas empleadas en la atención al parto; y d) Satisfacción de la puérpera sobre la atención. El estudio reveló que la mayoría de las puérperas tenían un buen nivel de satisfacción con relación a la atención obstétrica, pero todavía hay profesionales que recurren a técnicas intervencionistas innecesarias. Por esta razón, es esencial capacitar a los profesionales del equipo multidisciplinario de atención al parto, motivándolos a adoptar acciones y técnicas humanizadas y a implementar una efectiva educación en salud para mujeres embarazadas durante las consultas prenatales, para reconstruir su autonomía, optimizar su toma de decisiones con el equipo de salud y lograr un dominio completo de su propio cuerpo.

\section{INTRODUÇÃ 0}

As recomendações da Organização Mundial da Saúde (OMS) determinam que a assistência obstétrica pode ser iniciada antes do período gravídico para tentar atender a todas as necessidades maternoinfantis, visando ao bem-estar da mulher e do concepto no decorrer do trabalho de parto e no parto. Tais recomendações possibilitam a prevenção de complicações, além de preconizarem a humanização e o respeito à mulher no processo parturitivo, pois, desse modo, a adoção dessas práticas assegura procedimentos não intervencionistas, a fim de tornar o trabalho de parto e o parto um processo seguro para a mulher e seu bebê $\hat{e}^{1-2}$.

Em relação à implementação da assistência obstétrica segura e ao acolhimento da gestante no trabalho de parto e no parto, tem-se como referências, respectivamente, a portaria da Rede Cegonha e as Diretrizes Nacionais de Assistência ao Parto Normal, que visam a implementar os cuidados assistenciais corretos, a proteger e a assegurar às mulheres o direito à assistência integral no trabalho de parto, no parto e no puerpério, além da assistência humanizada e acolhedora e da garantia aos recém-nascidos do direito ao nascimento seguro e ao desenvolvimento saudável ${ }^{3-4}$.

0 termo humanização é empregado com frequência nos serviços públicos de saúde, mas não é assim que muitos profissionais atuam. Tal realidade é expressa por muitas pacientes, que revelam enfrentar discriminação e violação de seus direitos quando procuram atendimento, sendo este de péssima qualidade, o que gera situações de estresse, solidão, insegurança e absenteísmo entre as gestantes. A falta de acolhimento entre os profissionais e as gestantes 
pode acarretar a não adesão delas aos cuidados, devido à falta de orientação, de comunicação e de humanização $0^{5-6}$.

A fim de implementar práticas assistenciais mais adequadas, os profissionais da área obstétrica precisam planejar suas ações, implementando os cuidados recomendados em todo o processo de parto e de nascimento, viabilizando acolhimento e humanização de qualidade, definindo estratégias decisórias baseadas em evidências cientificas que favoreçam a assistência não intervencionista, respeitando os preceitos éticos e legais de autonomia da mulher e provendo resultados perinatais eficazes ${ }^{7}$.

Em tal sentido, inicialmente, esta pesquisa questionou: De que forma as puérperas vivenciaram a assistência obstétrica no processo parturitivo? Assim, adotou-se como questão norteadora: As puérperas perceberam como a atuação dos profissionais contribuiu para um trabalho de parto com práticas humanizadas e menos intervencionistas?

Dentre as razões que impulsionaram a escolha desse tema estão o interesse em estudar a percepção e a vivência da mulher no atendimento obstétrico durante o trabalho de parto, pois se sabe que as maternidades públicas atendem a um grande número de mulheres com baixo nível de escolaridade, baixa renda, problemas familiares e psicológicos, fatores que contribuem para que não tenham autonomia no cuidado de sua própria saúde, além de desconhecerem os serviços oferecidos na rede pública de saúde e os direitos que thes são garantidos no âmbito do Sistema Único de Saúde (SUS) ${ }^{4}$.

Com base no exposto, esta pesquisa teve por objetivo analisar a vivência das puérperas na assistência obstétrica recebida no processo parturitivo.

\section{METODOLOGIA}

Trata-se de estudo exploratório descritivo, com abordagem qualitativa. Em geral, as pesquisas qualitativas envolvem entrevistas com pessoas que estiveram no centro do problema de pesquisa. A abordagem qualitativa tem como característica 0 fato de que os pesquisadores estabelecem estratégias e procedimentos que thes permitem considerar as experiências sob o ponto de vista de quem lhes fornece a informação. Além disso, o processo de investigação reflete uma espécie de diálogo entre aqueles e os sujeitos ${ }^{8}$.

0 cenário desta pesquisa foi a maternidade

\section{A falta de acolhimento entre os profissionais $e$ as gestantes pode acarretar a não adesão delas aos cuidados...}

pública localizada na zona urbana de Caxias-MA, na região leste do estado, que à época tinha uma população estimada em 155.129 habitantes e uma área de $5.196,771 \mathrm{~km}^{2}$. Esse município se situa a 374 km da capital do Estado do Maranhão, São Luís, e a $70 \mathrm{~km}$ da capital do Estado do Piauí, Teresina9

Segundo os dados coletados de arquivos documentais, tal maternidade constitui referência em atendimento macrorregional de saúde, atendendo à população de 7 municípios da regional em questão, além de cerca de 47 municípios circunvizinhos. Na unidade ocorrem, em média, 288 partos/mês, com uma proporção de $46,19 \%$ de partos normais para $53,81 \%$ de cesáreas.

As participantes da pesquisa foram as puérperas assistidas durante seu trabalho de parto e seu parto na maternidade pública, dentre as quais foram convidadas 20, levando-se em conta o total de 134 partos normais ocorridos na referida instituição, sendo investigadas $15 \%$ das puérperas, às quais, ao participarem deste estudo, foram apresentados os principais pontos de abordagem (objetivos, justificativa e outras informações relevantes sobre a pesquisa) e elas tiveram suas dúvidas esclarecidas.

Os critérios de inclusão definidos para esta pesquisa englobaram puérperas: a) maiores de 18 anos; b) que fizeram uso dos serviços de assistência à saúde no trabalho de parto e no parto vaginal no centro obstétrico; e c) residentes nos municípios atendidos pela maternidade onde se desenvolveu a pesquisa.

Já o critério de exclusão consistiu em puérperas que vivenciaram o parto por via vaginal com complicações maternas e fetais.

A coleta de dados ocorreu em dezembro de 2019 e janeiro de 2020, no alojamento conjunto da maternidade, em horários nos quais as puérperas puderam ser visitadas e entrevistadas. 0 instrumento adotado para a coleta de dados foi o roteiro de entrevista aberto, permitindo que a puérpera expressasse livremente sua experiência no processo parturitivo na referida maternidade pública. 
Em seguida, todas as informações obtidas com o roteiro de entrevista foram submetidas à técnica de Análise de Conteúdo, na modalidade análise categorial, seguindo a ordem em que as observações foram feitas, demonstrando a importância de cada aspecto observado para o desenvolvimento do trabalho na referida instituição.

A Análise de Conteúdo tem por propósito a compreensão do significado das falas dos sujeitos para além dos limites daquilo que é descrito. Recorreu-se à modalidade análise categorial para reunir em grupos maiores diversos pensamentos e ideias, unidades de registro ou temas, ou seja, nas chamadas categorias, considerando as afinidades e as disparidades entre os temas e a dependência dos critérios de classificação, daquilo que se procura e daquilo que se espera encontrar ${ }^{10}$.

Ressalta-se que, para facilitar a compreensão das informações, os dados foram fielmente descritos e, em seguida, cada participante foi identificada no texto como P1 (Puérpera 1), P2 (Puérpera 2), e assim sucessivamente.

0 estudo obteve aprovação por meio do Parecer $n$. 3.471.269/2019 e do Certificado de Apresentação para Apreciação Ética (CAAE) n. 17355719.4.0000.5554. Foram observados todos os preceitos éticos determinados pela Resolução 466/2012, do Conselho Nacional de Saúde (CNS), do Ministério da Saúde (MS).

\section{RESULTADOS E DISCUSSÃO}

As informações colhidas permitiram a análise do perfil das 20 puérperas entrevistadas, o que revelou uma amostra composta por mulheres entre 19 e 36 anos de idade, cujo estado civil se distribuiu da seguinte forma: a) $65 \%$ em união estável; b) $20 \%$ casadas; e c) $15 \%$ solteiras.

Quanto à escolaridade das entrevistadas: a) $5 \%$ concluíram o Ensino Fundamental; b) $20 \%$ têm o Ensino Fundamental incompleto; c) $45 \%$ têm 0 Ensino Médio incompleto; d) $20 \%$ têm o Ensino Médio completo; e) $5 \%$ têm o Ensino Superior completo; e f) $5 \%$ têm o Ensino Superior incompleto. Em relação à ocupação: a) $65 \%$ são do lar; b) $15 \%$ são lavradoras; c) $5 \%$ são secretárias escolares; d) $5 \%$ são empregadas domésticas; e) $5 \%$ são cabeleireiras; e f) $5 \%$ são estudantes.

Tendo por base os relatos e as respostas das participantes à questão proposta no roteiro de entrevista, procedeu-se à categorização, usando

\author{
Percebe-se que a \\ satisfação das mulheres \\ se refere à obtenção \\ de atendimento \\ profissional...
}

os momentos relativos a cada fase do processo parturitivo em que é prestada assistência às gestantes na maternidade e as condutas adotadas, para gerar uma organização textual que proporcionasse melhor compreensão da pesquisa, além de permitir as análises conforme a metodologia proposta.

\section{Atendimento no acolhimento e classificação de risco da maternidade}

Ao entrar na maternidade, a maioria das mulheres relata o atendimento dos enfermeiros e médicos no acolhimento e classificação de risco da maternidade. 0 atendimento compreendeu em suas falas, principalmente, a realização do exame de toque vaginal, da ausculta dos batimentos cardiofetais, do encaminhamento para a ultrassonografia (quando necessário) e das orientações.

Quando cheguei, por volta das 4:40 horas $d a$ tarde, uma enfermeira me examinou, depois o médico fez o toque em mim, foi super gente boa, depois disso fui para a sala do pré-parto. (P4)

Cheguei à maternidade por volta das 3:30 horas da manhã, fui atendida pelo doutor, não lembro o nome, foi feito o toque, ele me encaminhou para a sala de pré-parto. (P5) Cheguei no dia 7 de janeiro, às 10 horas da manhã, fui recebida pela enfermeira que me passou para o médico, que fez o exame de toque; logo em seguida me mandou para a sala de pré-parto, explicou o procedimento do exame antes de fazê-lo. (P13)

Cheguei à maternidade umas 8 horas $d a$ manhã de domingo, a avaliação foi ótima, ela passou um ultrassom para saber como estava o bebê, me explicou tudo direitinho, me deixou de avaliação. (P18)

Percebe-se que a satisfação das mulheres se refere 


\section{...é perceptivel a importância dada pelo enfermeiro obstetra à orientação das parturientes...}

à obtenção de atendimento profissional, ao tempo de espera para ele, aos exames e às avaliações feitas. Não se observou nesses relatos condutas sobre o profissional haver se apresentado e cumprimentado a paciente. De acordo com as recomendações do MS, as mulheres em trabalho de parto devem ter acesso às informações baseadas em evidências e devem ser incluídas na tomada de decisões, cabendo aos profissionais estabelecer uma relação de confiança com elas 4

Depreende-se do exposto, ainda, a forte presença de uma assistência focada apenas em atender ao problema de saúde da paciente, na qual os profissionais não se preocupam em extrair da gestante suas dúvidas, vontades, sentimentos e crenças, sendo perceptível que a assistência à saúde de forma humanizada e acolhedora ainda não chegou ao patamar recomendado. 0 acolhimento se baseia em ações como a presença constante, a atenção dispensada, o diálogo e mesmo pequenos atos, como o contato físico, pois ultrapassam as barreiras entre o profissional e a parturiente, estabelecendo uma relação de confiança e de troca, ou seja, apoio emocional ${ }^{11}$.

Assim, a atenção humanizada e de boa qualidade implica no estabelecimento de relações entre sujeitos, seres semelhantes, ainda que possam mostrar-se muito distintos em termos de condições sociais, raciais, étnicas, culturais e de gênero ${ }^{12}$.

\section{Técnicas e condutas empregadas na assistência pré-parto}

Diante dos relatos, é perceptível a importância dada pelo enfermeiro obstetra à orientação das parturientes sobre a realização de exercícios e a adoção de posições verticalizadas, acompanhadas de explicações quanto aos benefícios e aos resultados esperados com a adoção dessas práticas. Destaca-se, também, o respeito dos profissionais ao deixarem que as pacientes adotem as posições desejadas por elas e que, segundo relatam, pareciam-lhes mais confortáveis - inclusive permanecerem deitadas no leito.

Falaram para eu caminhar ou agachar, mas eu disse que não aguentava, fiquei no préparto deitada. (P1)

Falou para fazer bastante exercício para a bebê descer, para a bolsa estourar, mexer para um lado e para o outro e fazer agachamento. (P2)

Não orientou a caminhar, só mesmo a respiração, fiquei o tempo todo deitada, a dor estava muito forte, não aguentava levantar. (P5)

Me colocaram no leito, ela falou para eu ficar deitada de lado, veio uma médica, também, ela falou para eu ficar na posição que eu achasse melhor para mim, não orientaram a caminhar, só ficar deitada, fiquei sempre deitada, eu ia só ao banheiro porque eu tinha vontade de urinar toda hora. (P14)

Depois que a enfermeira veio, falou que eu poderia fazer exercício, mas se não quisesse eu poderia ficar deitada, falou para caminhar $e$, se sentisse dor, para levantar as pernas, eu quis ficar só deitada mesmo. (P17)

Um estudo corrobora isso ao enfatizar que a mulher deve ser assistida com delicadeza, sendo respeitado o seu tempo, propiciando-lhe a redução da dor por meio de exercícios, massagens, banhos, deambulação e aceitação de posições de livre escolha da parturiente no processo parturitivo ${ }^{13}$.

A maior parte das pacientes fez os exercícios e as posições depois de terem sido orientadas, demonstrando não conhecerem essas práticas nem seus benefícios, e também demonstraram não saber que tinham autonomia para decidir as posições desejadas. Das entrevistadas, apenas uma mencionou conhecer os exercícios e uma se manteve em caminhada mesmo não tendo recebido orientação, como demonstram as falas:

Eu fiquei deitada, depois desci da cama, caminhei um pouco, ela não me disse para andar, andei por conta própria, não fiz exercício, não fiz agachamento. (P10) Minha mãe falou que eu era formada em fisioterapia, que eu poderia fazer os exercícios. Comecei a fazer caminhada, 
agachamento, mandei minha mãe fazer massagem onde estava doendo, aqui atrás. (P3)

Vale ressaltar que a assistência pré-natal deve inserir com maior intensidade a educação e a informação coletiva ou individual sobre o trabalho de parto, incluindo os direitos e a prática de fazer movimentos, exercícios e posições que contribuem para a boa evolução do trabalho de parto e do parto. Considera-se que a educação em saúde proporciona conhecimento crítico e reflexivo, estimulando a independência dos indivíduos sugestionados a produzir um saber que colabore com a prática do autocuidado ${ }^{13}$.

Foi relatada grande frequência de amniotomias. Tal procedimento só deve ser feito quando avaliada sua necessidade, pois a amniotomia precoce não deve ser praticada de forma rotineira em mulheres em trabalho de parto com boa progressão ${ }^{4}$.

Também se notou que houve oferta de líquidos e refeições durante todo o processo parturitivo, revelando-se a adequação da maternidade e dos profissionais às boas práticas de assistência ao parto.

Achei que fizeram muitos toques, me incomodou, mas, como eram os profissionais, acredito que eram necessários para que me ajudassem a ter meu bebê. A bolsa foi estourada pelo profissional. Bebi água, comida não consegui comer, mas me ofertaram comida. (P5)

Fizeram toque, disseram que eu não estava em trabalho de parto. Fizeram toque, bem umas dez vezes, fizeram muitos toques, era um toque atrás do outro, eu estava muito desesperada, com muito calor e nada de dor e toda hora eles iam dá um toque: "pois pronto, não vou parir mais, não, estou toda ardida só de toque". Minha bolsa rompeu naturalmente. 0 médico fez muito toque, pedi para ele não tocar porque estava doendo muito, mas ele tocou. (P6)

Me deram água, não consegui comer porque não descia, só consegui beber um pouco de água. Fizeram toques, acho que o tanto normal, porque só deixei fazer dois, eu que deixei fazer, não insistiam quando não deixava fazer. Escutaram os batimentos do coração do bebê, falaram que estava normal e que era para eu deitar sempre do lado esquerdo que ajudava na respiração dele. (P7)

Ela falou para mim que eu estava bem dilatada, o que podia fazer era só ela estourar a bolsa para eu poder ter rápido, porque o que estava empatando era só a bolsa romper, aí primeiro eu disse: "não, vamos demorar mais um tempo". Depois ela voltou: "agora vamos, porque não podemos ficar até esse tempo todinho", porque se demorasse demais poderia ter que ir para algum medicamento. (P16)

Vê-se que ainda não há uma assistência completamente humanizada, pois são identificados resquícios de uma assistência tecnicista, que desvaloriza a autonomia da parturiente. Isso é confirmado pelos relatos, ao se verificar o excesso de amniotomias e de toques vaginais. Embora a maior parte das pacientes tivesse suas vontades respeitadas, percebemos que ainda há uma parte dos profissionais que não adotam tal conduta, contrariando as decisões da paciente quando elas não permitem certos procedimentos.

Diante disso, mais uma vez se destaca a importância de proporcionar informação às gestantes. A enfermeira especialista desempenha um papel fundamental na mudança de comportamento das gestantes, proporcionando-lhes informações sobre recursos e competências, mas existem, ainda, dificuldades quanto à desconstrução da falta de autonomia da mulher em relação aos profissionais, faltando, assim, escolhas conscientes e de controle do próprio corpo, indispensáveis no processo de trabalho de parto e no parto ${ }^{14}$.

\section{Técnicas e condutas empregadas na assistência ao parto}

Pelas falas, nota-se a adoção constante de ações que respeitam a fisiologia do parto natural, sem

$$
\begin{gathered}
\text {... a educação em } \\
\text { saúde proporciona } \\
\text { conhecimento crítico } \\
\text { e reflexivo... }
\end{gathered}
$$


recurso a técnicas intervencionistas e invasivas. Contudo, durante o parto, que compreende o período expulsivo do concepto, houve predominância de partos feitos em posições supinas e o estímulo à realização de puxos dirigidos, como se observa nas falas:

Me levaram para a sala, me botaram na posição normal, deitada, falavam: "bota força Maria, bota força que o neném está vindo"; ai ela fazia "assim" na minha vagina, pegando na minha vagina, acho que era para abrir mais um pouco. (P6)

Me botaram na posição de bandinha, deitada de lado, achei melhor, não precisou pegar ponto. (Pg)

Me colocaram deitada, as pernas ficaram em cima daquele suporte, falavam para botar força, quando vier a dor mesmo aí botava força, não fizeram corte, não, fizeram só pontear. (P10)

Fiquei deitada, depois pedi para ficar de banda, quando fiquei de banda demorou pouco o menino nasceu, foi melhor essa posição. (P16)

Nesses relatos se nota que as mulheres estão condicionadas a adotar a posição supina ginecológica imposta pelo modelo biomédico. Nesse quesito, é necessário que os profissionais estimulem mais a adoção de posições verticalizadas durante o porto, informando às pacientes como elas podem contribuir para a melhor progressão do segundo período do parto e para o conforto da paciente, não limitando essas posições ao momento do trabalho de parto. Desse modo, a escolha da posição do parto compreende uma relação livre de qualquer ato de coerção ou autoritarismo e imposições, com escolhas conforme as necessidades mais convenientes e confortáveis ${ }^{14}$.

Vale ressaltar que as posições não supinas estão associadas à diminuição da duração do período expulsivo e à necessidade de episiotomia, o que facilita o processo fisiológico do parto, pois relaxa a pelve, aumenta a liberdade de movimento e a flexibilidade do quadril, o que incide no auxílio na rotação da apresentação fetal. Registra-se, também, que o posicionamento horizontal está relacionado à maior compressão da artéria aorta e da veia cava, dificultando a troca gasosa entre o binômio mãe e filho e à menor efetividade das contrações uterinas ${ }^{15}$.

A presença de esforços de puxos prolongados

\section{...as mulheres estão condicionadas a adotar a posição supina ginecológica imposta pelo modelo biomédico...}

e dirigidos foi apontada em algumas falas da pesquisa. Em estudo quantitativo, descritivo e exploratório, feito com 25 puérperas, registrou-se que, na percepção delas sobre os cuidados recebidos por enfermeiros obstetras, $100 \%$ destacaram 0 ensinamento de "botar força" para facilitar a expulsão do bebê, sendo que 95,7\% afirmaram que sempre foram ensinadas e motivadas a fazer força de acordo com os puxos e a respiraçã $0^{13}$.

Com frequência menor, houve relatos sobre 0 procedimento de episiotomia nos quais se nota que ele foi empregado de forma injustificável na maioria dos casos, seja por médicos ou enfermeiros obstetras, que também realizam a manobra de Kristeller:

Fiquei deitada quase sentada, com as pernas levantadas, o médico fez meu parto, falava para eu colocar força e a questão para eu controlar a minha respiração, porque ao invés de eu colocar força para baixo eu ficava respirando e ele falou que não iria me ajudar. Ele fez o corte e anestesiou para ajudar a criança a nascer, ai depois foi ponteado. (P5)

Me levaram para a sala de parto, chegou lá e ele já estava só no ponto de nascer, só que eu já estava sem força, me deram a injeção para força, mas mesmo assim não consegui, a enfermeira me ajudou a colocar a neném para fora, me cortaram, ela empurrava aqui em cima, foi melhor, porque eu estava sem força. (P11)

Foi a enfermeira obstetra que fez meu parto, ela falava para eu botar força para o bebê sair, a posição foi com as pernas abertas quase sentada, segurando as pernas, eu preferi ficar sentada estava ajudando mais, cortaram a vagina, ela explicou na hora, era para ajudar o bebê a sair. (P13)

Apesar da recomendação da OMS quanto ao 


\section{...houve significativa atenção para proporcionar o contato pele a pele entre mãe e recém- nascido...}

uso rotineiro ou liberal da episiotomia, ele não é recomendado para mulheres que evoluem para parto vaginal espontâneo, pois não há evidências que corroborem a necessidade desse procedimento nos cuidados de rotina, embora essa prática ainda seja costumeira para muitos profissionais ${ }^{16}$.

Um estudo identificou que a prática da episiotomia foi realizada em $28 \%$ dos partos ${ }^{15}$. Diante disso, mostra-se importante a conscientização e a capacitação dos profissionais de saúde para a necessidade de empreenderem maiores esforços a fim de atingir a meta estipulada pela OMS, garantindo a qualidade da assistência obstétrica e levando em conta que, de acordo com essa organização, caso uma episiotomia seja feita, a anestesia local efetiva e o consentimento informado da mulher são essenciais ${ }^{16-17}$.

Em contrapartida aos procedimentos citados que não devem ser praticados, houve significativa atenção para proporcionar o contato pele a pele entre mãe e recém-nascido, conduta mantida em todos os partos nos quais o concepto nasceu sem intercorrências em sua vitalidade.

Pari deitada; quando nasceu botaram a neném em cima de mim, depois a enfermeira a levou para pesar e botar a fralda. (P17)

Colocaram a bebê em cima de mim, falaram para colocar no peito e falavam "respira fundo". Botei ele no peito lá mesmo, quando nasceu. (P18)

Colocou ela no meu colo, disse que era bom para o bebê ter aquele toque, para sentir o calor da mãe naqueles primeiros minutos, que era importante, fiquei com ela no meu colo e logo após ela levou, disse que iria medir o peso, essas coisas. (P20)

A prática do contato pele a pele é avaliada como um ponto positivo no atendimento proporcionado às parturientes, uma vez que é de conhecimento geral que, nos primeiros minutos de vida, os bebês devem ser colocados junto à mãe de forma contínua, pois esse contato beneficia o aumento de alguns hormônios que estimulam o estabelecimento do vínculo mãe-filho e o reflexo da descida do leite, facilitando a amamentação na primeira hora de vida. Além disso, o contato pele a pele proporciona proteção e calor ao recém-nascido ${ }^{15}$.

\section{Satisfação da puérpera sobre a assistência}

A maioria das entrevistadas demonstrou bom nível de satisfação diante da assistência obstetra, relatando como as orientações dos profissionais e, mais predominantemente, aquelas oferecidas pelo enfermeiro obstetra as ajudaram a adquirir confiança e as tranquilizaram diante do trabalho de parto e do parto. A companhia do enfermeiro e sua presença sempre próxima e ativa foi bastante mencionada nas falas:

Por volta de 1:40 hora da manhã a minha filha nasceu e, sempre com a orientação desse enfermeiro. Não fiquei com medo, estava confiante, os profissionais me acalmavam. Achei o atendimento bom, me trataram superbem, eu gostei muito, não tive problemas com o pessoal, cuidaram bem de mim. (P4)

A enfermeira me ajudou, ajudou a criar coragem, ela mandou "criar coragem". 0 atendimento foi bom, eu só fiquei indecisa por causa da bolsa, mas ela falou que já estava tudo dilatado e não iria demorar, e ela falou a verdade. (P16)

Eu achei o atendimento bom, eu não tenho queixas. (P20)

Também foi possível identificar a decepção das pacientes quanto ao tratamento inadequado e ao período de ausência e à desatenção dos profissionais, demonstrada nos diálogos:

No início eu não gostei muito do atendimento, não, por que eles não iam me dar informação de nada, mas no final eles começaram a me atender bem, o doutor me acompanhou até o fim. (P3)

A assistência foi legal, só não gostei do segundo médico, quando eu voltei para a maternidade para ficar, ele foi um pouco 
grosseiro, o jeito que ele foi comigo eu fui com ele também, o tom de voz dele, o jeito que ele é, meu Deus! o primeiro não, ele conversou direitinho, me explicou, o segundo nem explicou nada, ele só escrevia lá. (P7) Ele não deu orientação quando terminou de dar os pontos, só se levantou, saiu emburrado, ele estava muito grosseiro porque eu falei que estavam doendo os pontos, ele falou que era mentira minha, que não estava doendo, não. (P17)

Conclui-se que a satisfação das pacientes advém da percepção da companhia do profissional de saúde, não só na oferta de orientações, mas as ajudando em sua execução. Observa-se que essas mulheres referem medo, insegurança, preocupação e dor no processo parturitivo, mas a assistência obstétrica prestada de forma qualificada e humanizada ameniza tais sentimentos. A paciência e a calma da equipe de enfermagem provocaram sentimentos de satisfação, o que contribui para a redução dos níveis de ansiedade antes do parto ${ }^{14}$.

Diante dos relatos que manifestaram o motivo da insatisfação, vale destacar que mediante informações geradoras de empoderamento das mulheres durante o pré-natal se pode prevenir condutas inapropriadas na assistência à saúde. A assistência qualificada no pré-natal minimiza riscos, garante direitos e promove educação em saúde ${ }^{13}$.

\section{CONCLUSÃO}

Verificamos que a maioria das puérperas entrevistadas apresentava, por suas vivências, um bom nível de satisfação diante da assistência obstétrica. Nota-se que as puérperas avaliam a assistência mais pela forma como são tratadas, ou seja, por meio da educação e do diálogo com o profissional, e menos pelos procedimentos realizados, não levando em conta o conjunto de ações que tornam a assistência um processo humanizado, revelando que desconhecem: a) seus direitos; b) o que são técnicas invasivas; e c) o que são técnicas desnecessárias e não preconizadas no trabalho de parto e no parto.

Mostra-se necessário redirecionar o foco para a existência de deficiências relativas à educação, proporcionando informações cruciais às mulheres e aos seus familiares durante o pré-natal acerca de práticas, condutas e direitos que devem fazer parte da assistência ao trabalho de parto. Maior atenção para a implantação mais eficiente de educação em saúde voltada à gestante serve para: a) reconstruir sua autonomia; b) otimizar sua tomada de decisões junto à equipe de saúde; e c) alcançar pleno domínio de seu próprio corpo.

Observou-se o acolhimento, o vínculo, o contato físico, o esclarecimento de dúvidas e a minimização de ações intervencionistas na maior parte da assistência de enfermagem. A maioria das puérperas teve suas expectativas atendidas quanto aos cuidados durante o trabalho de parto e o pósparto e elas se mostraram muito satisfeitas diante da assistência do enfermeiro obstetra e da equipe de enfermagem.

\section{CONTRIBUIÇÃO DAS AUTORAS}

Quelrinele Vieira Guimarães, Luana Pereira Ibiapina Coêlho e Monyka Brito Lima dos Santos contribuíram com a realização da pesquisa, o delineamento do estudo e a redação do manuscrito. Beatriz Mourão Pereira, Ana Carla Marques da Costa e Joanne Thalita Pereira Silva contribuíram com o delineamento do estudo e a redação e revisão crítica do manuscrito.

\section{REFERÊNCIAS}

1. Alves CC, Cavalcante MMB, Sampaio ACC, Aragão HL, Oliveira EM, Teixeira MA. Humanização do parto a partir de métodos não farmacológicos para o alívio da dor: relato de experiência. Sanare (Sobral, Online) [serial on the internet]. 2015 [cited 2019 0ct 16];(14):70-4. Available from: https://sanare. emnuvens.com.br/sanare/article/view/870

2. Freire H, Campos F, Castro R, Costa C, Mesquita V, Viana R. Normal birth assisted by nurse: experience and satisfaction of puerperals. Rev Enferm UFPE On Line [serial on the internet]. 2017 [cited 2020 Feb 28];11(6):2357-67. Available from: https:// periodicos.ufpe.br/revistas/revistaenfermagem/ article/view/23398

3. Martins EG. Assistência ao trabalho de parto e parto acompanhado pela enfermeira obstétrica: olhar das puérperas. Cadernos ESP: Revista Científica da Escola de Saúde Pública do Ceará [serial on the internet]. 2016 [cited 2020 Jan 28];10(2):22-32. Available from: http://cadernos.esp.ce.gov.br/ index.php/cadernos/article/view/104

4. Brasil. Diretrizes nacionais de assistência ao parto normal: versão resumida. Brasília (DF): Ministério da Saúde; 2017. 
5. Correia S, Santos A, Silva J, Comassetto I, Lima G, Ferreira D. Cuidados de enfermagem prestados à parturiente adolescente sob a luz da Teoria de Wanda Horta. Rev Pesqui (Univ Fed Estado Rio J, Online) [serial on the internet]. 2017 [cited 2020 Jan 28];9(3):857-66. Available from: http://www. seer.unirio.br/index.php/cuidadofundamental/ article/view/5574

6. Rocha AC, Andrade GS. Nursing team attention during prenatal: perception of pregnant women assisted in basic network at Itapuranga-GO in different social contexts. Revista Enfermagem Contemporânea [serial on the internet]. 2017 [cited 2019 0ct 21];6(1):30-41. Available from: https:// www5.bahiana.edu.br/index.php/enfermagem/ article/viewFile/1153/846

7. Ragagnin M, Marchiori M, Diaz C, Nicolli T, Pereira $S$, Silva L. Abordagem da equipe de enfermagem acerca do parto humanizado no pré-natal: uma revisão narrativa. Rev Pesqui (Univ Fed Estado Rio J, Online) [serial on the internet]. 2017 [cited 2019 Nov 8];9(4):1177-82. Available from: http:// www.seer.unirio.br/index.php/cuidadofundamental/ article/view/6394

8. Dyniewicz AM. Metodologia da pesquisa em saúde para iniciantes. São Caetano do Sul (SP): Difusora; 2009.

9. Instituto Brasileiro de Geografia e Estatística. Cidades: Caxias [document on the internet]. 2019 [cited 2020 Nov 2]. Available from: IBGE https:// cidades.ibge.gov.br/brasil/ma/caxias/panorama

10. Bardin L. Análise de conteúdo. São Paulo: Ed. 70; 2011.

11. Souza C, Ferreira C, Barbosa N, Marques J. Nursing staff and the care devices in the childbirth process: focus on humanization. Rev Pesqui (Univ Fed Estado Rio J, Online) [serial on the internet]. 2013 [cited 2020 Feb 28];5(4):743-54. Available from: http:// www.seer.unirio.br/index.php/cuidadofundamental/ article/view/2380

12. Brasil. Política Nacional de Atenção Integral à Saúde da Mulher: princípios e diretrizes [document on the internet]. 2011 [cited 2019 Jun 16]. Available from: http://bvsms.saude.gov.br/bvs/publicacoes/ politica nacional mulher principios diretrizes.pdf

13. Ribeiro J, Oliveira K, Lira J, Chagas D, Branca $S$, Lima $F$, et al. Contentment of puerperal women assisted by obstetric nurses. Rev Enferm UFPE On Line [serial on the internet]. 2018 [cited 2020 Jan 28];12(9):2269-75. Available from: https:// periodicos.ufpe.br/revistas/revistaenfermagem/ article/view/234777

14. Silva AB, Albuquerque NLA, Carvalho ACS, Silva
RDM, Vicente CD. Percepção da mulher acerca da assistência ao parto pela enfermeira obstetra. Enferm Foco (Brasilia) [serial on the internet]. 2018 [cited 2020 Feb 11];9(4):28-33. Available from: https:// www.researchgate.net/publication/330041319 PERCEPCA0 DA MULHER ACERCA DA ASSISTENCIA AO PARTO PELA ENFERMEIRA OBSTETRA

15. Romão RS, Fuzissaki MA, Prudêncio PS, Freitas EAM. Qualidade da assistência obstétrica relacionada ao parto por via vaginal: estudo transversal. Revista de Enfermagem do Centro-0este Mineiro [serial on the internet]. 2018 [cited 2020 Feb 5];(8):e2907. Available from: http://seer.ufsj.edu.br/index.php/ recom/article/view/2907/2048

16. Organização Mundial da Saúde. Cuidados no trabalho de parto e parto: recomendações da OMS [document on the internet]. 2018 [cited 2019 Apr 16]. Available from: https://www.febrasgo.org.br/ pt/noticias/item/556-cuidados-no-trabalho-departo-e-parto-recomendacoes-da-oms

17. Pompeu KC, Scarton J, Cremonese L, Flores RG, Landerdahl MC, Ressel LB. Prática da episiotomia no parto: desafios para a enfermagem. Revista de Enfermagem do Centro-0este Mineiro [serial on the internet]. 2017 [cited 2020 Feb 8];(7):e1142. Available from: http://www.seer.ufsj.edu.br/index. $\mathrm{php} / \mathrm{recom} / \mathrm{article} / \mathrm{view} / 1142$
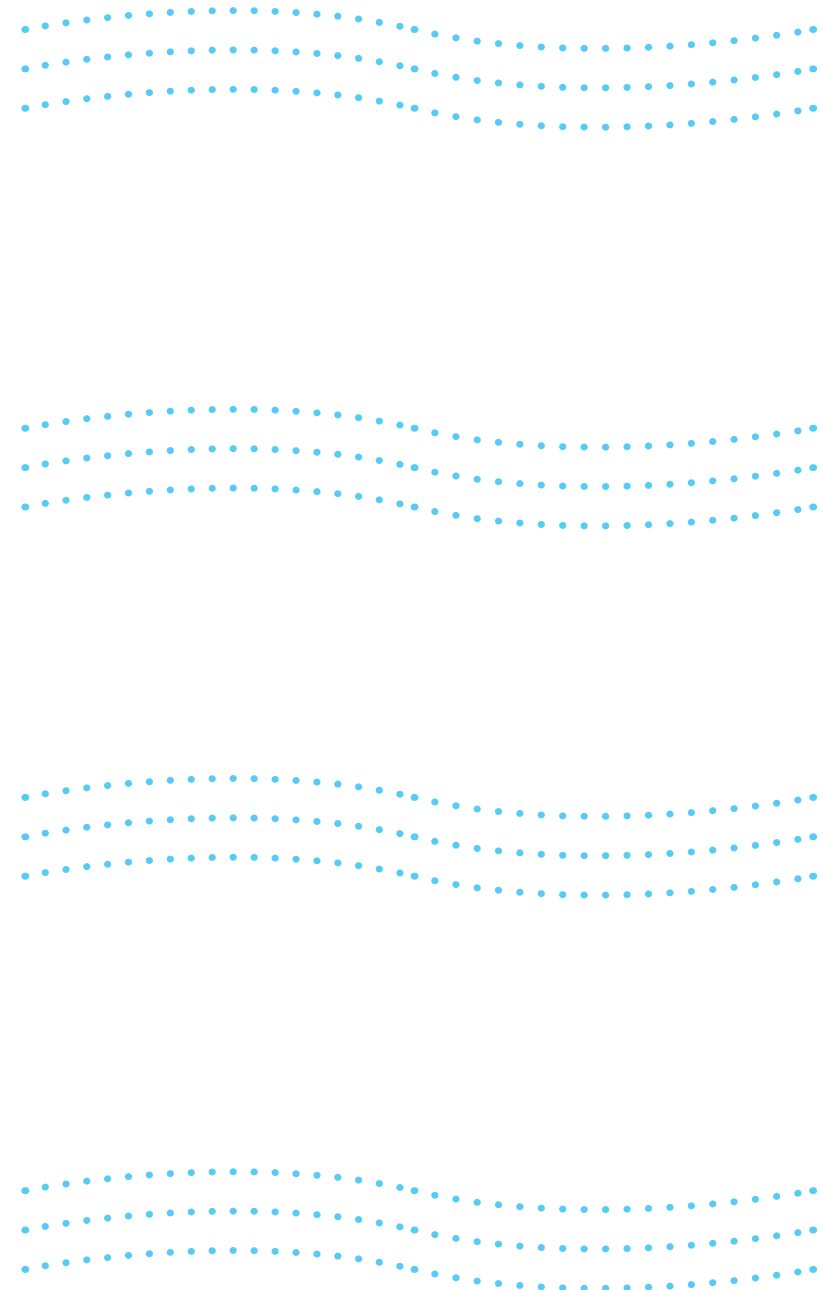

SANARE (Sobral, Online). 2020 Jan-Jun;19(1):48-57 - 57 